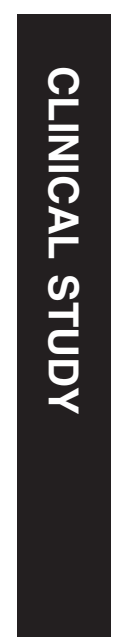

\title{
Effects of head elevation on intraocular pressure in healthy subjects: raising bed head vs using multiple pillows
}

D-Y Yeon ${ }^{1}, C_{\text {C Yoo }}^{1}$, T-E Lee ${ }^{2}$, J-H Park ${ }^{1}$

and $Y Y$ Kim $^{1}$

\begin{abstract}
Purpose To evaluate the effects of different methods of head elevation on intraocular pressure (IOP) in healthy young subjects. Methods Twenty-four healthy young Korean subjects were included in this prospective observational study. The IOP measurements were taken with the subjects in the sitting position and in the supine positions with the head flat and $30^{\circ}$ up using two different methods: (1) raising the bed head and (2) using multiple pillows. IOP was measured using Tonopen AVIA in both eyes $10 \mathrm{~min}$ after assuming each position in a randomized sequence. The Wilcoxon signed-rank test was used to compare the IOP by changing the
\end{abstract}

${ }^{1}$ Department of Ophthalmology, Korea University College of Medicine, Seoul, Korea

${ }^{2}$ Department of Ophthalmology, Samsung Medical Center, Sungkyunkwan University College of Medicine, Seoul, Korea

Correspondence: C Yoo, Department of Ophthalmology, Korea University College of Medicine, 126-1 Anam-dong 5-ga, Sungbuk-gu, Seoul 136-705, Korea Tel: +82 2920 6774; Fax: +82 29246820 E-mail: augen@lycos.co.kr

Received: 28 April 2014 Accepted in revised form: 2 August 2014

Published online:

5 September 2014 methods of head elevation.

Results Mean IOP of both eyes when sitting was lower than that measured in the supine position with head flat $(P=0.001)$. Compared with that measured in the supine position with head flat, the mean IOP was lower when measured in the supine position with the head kept $30^{\circ}$ up by bed head elevation $(P=0.001)$, whereas the mean IOP was not significantly different when measured in the supine position with the head elevated using multiple pillows (right eye, $P=0.061$; left eye, $P=0.089$ ). Conclusion In normal subjects, IOP was lower when measured in the supine position with the head kept up by the bed head elevation compared with that measured when lying flat. However, such head-up positioninduced IOP reduction was not found when the head was kept up using multiple pillows. These findings suggest that elevating the head using multiple pillows may not help to reduce IOP in the supine posture.
Eye (2014) 28, 1328-1333; doi:10.1038/eye.2014.211; published online 5 September 2014

Introduction

Elevated intraocular pressure (IOP) has been shown to influence the development of glaucomatous optic neuropathy. ${ }^{1,2}$ In addition to elevated IOP, factors such as ocular blood flow, ${ }^{3}$ racial factors, ${ }^{4}$ refractive errors, ${ }^{5}$ genetic factors, ${ }^{4}$ and low cerebrospinal fluid pressure ${ }^{6}$ have been associated with the glaucoma pathogenesis. However, IOP is the only modifiable risk factor; IOP lowering is the only proven therapy to prevent or slow down the development or progression of glaucoma. ${ }^{1,2,7}$

The different means of lowering IOP include medication, laser treatments, and filtering surgery. ${ }^{8}$ Among these modalities, medical therapy is usually the first choice because one can avoid potential vision-threatening complications that may occur after surgical interventions. Although medical therapy has been shown to effectively reduce IOP, it often fails to prevent the progression of glaucoma because of poor compliance, local or systemic adverse effects, and non-responsiveness.

Glaucoma may even progress in some patients despite medically well-controlled office IOP. ${ }^{7}$ Because glaucoma is a chronic progressive disease and laser or surgical treatments do not always provide a total cure, it would be good to have another means of lowering IOP before moving on to surgical options.

Similar to management of glaucoma, the mainstay of systemic hypertension management is blood pressure-lowering medication. However, if a patient newly diagnosed as 
systemic hypertension has mild risk factors and the degree of blood pressure elevation is not severe, lifestyle modification (for example, quit smoking, avoid fat-rich meals, or do regular physical exercises) is usually recommended before commencing medical treatment. ${ }^{9}$ Lifestyle modification is also recommended to patients with systemic hypertension who begin to take antihypertensive medication. Thus, it would be useful for management of glaucoma patients if modification of a certain factor in his or her lifestyle helps to reduce IOP.

Body posture is one of the factors influencing the fluctuation of IOP. ${ }^{10}$ Compared with the upright posture, IOP has been shown to increase in the horizontal postures (supine, ${ }^{11-17}$ prone, or lateral decubitus ${ }^{18-24}$ ) in healthy and glaucomatous eyes. Such posture-induced IOP rise has been associated with progression of glaucomatous damage. ${ }^{21,22,25}$ Some researchers studied the effect of sleeping in a head-up position using a wedge pillow in glaucoma patients ${ }^{26,27}$ and healthy subjects, ${ }^{27}$ and they demonstrated reduction of mean IOP by 1.5-3.2 $\mathrm{mm} \mathrm{Hg}$ in the head-up position compared with the flat position. However, keeping the head up can be achieved by other methods such as using multiple pillows (MP) or raising the head of the bed.

We conducted this study to investigate the effects of head elevation on IOP in healthy young subjects and compare the two different methods of head elevation in their effects on IOP.

\section{Materials and methods}

This is a prospective, observational study. Ethical approval was obtained from the institutional review board of the Korea University Anam Hospital. The study was conducted in adherence to the tenets of the World Medical Association's Declaration of Helsinki. Written informed consent was provided by each subject before participating in the study. We recruited healthy Korean adults younger than 40 years. Each participant had completed a general physical check-up within 1 year, demonstrating the absence of any systemic disease. The subjects underwent comprehensive ophthalmic examinations.

Subjects were excluded if they met one of the following criteria: (1) presence of retinal disease; (2) previous ocular surgery; (3) family history of glaucoma; (4) best-corrected visual acuity <20/40; (5) IOP of $22 \mathrm{~mm} \mathrm{Hg}$ or greater; (6) refractive error exceeding a spherical equivalent of 9 diopters or astigmatism of 2 diopters; (7) trabecular meshwork not visible in any quadrant on static gonioscopy; or (8) glaucomatous optic disc changes, such as excavation, thinning, or notching of the neuroretinal rim, and disc hemorrhages.

IOP measurements were conducted between 1800 and 2000 hours. A single observer measured IOP in both the eyes using a single Tonopen AVIA (Reichert Inc., Depew, NY, USA) for each position. IOP readings were obtained in the right eye first. Proparacaine hydrochloride $0.5 \%$ solution was used as a local anesthetic. The Tonopen was calibrated in accordance with the Tonopen AVIA manual before the measurements for each posture were taken. Measurements were made with the probe perpendicular to the corneal plane and along the visual axis. IOP value for each posture was the mean of two consecutive measurements that were within $2 \mathrm{~mm} \mathrm{Hg}$ and that had $<5 \%$ error as indicated on the Tonopen or the median of three measurements if the first two differed by $3 \mathrm{~mm} \mathrm{Hg}$ or more. ${ }^{28}$

To allocate a randomized sequence of IOP measurements in different recumbent positions (1) flat, (2) head-up with bed head elevation (BHE), or (3) headup with MP, each subject was asked to pick one card, where different positions were written on the back, one after another until all the three cards were open. Thus, each participant was informed about the sequence of changing the aforementioned recumbent postures. Before commencement of the IOP measurements, the subjects were rested with the bed head $30^{\circ}$ elevated and the level (height from the ground) of the subject's eyes was marked on the wall so that the level of the eyes thus obtained should be equally as high as that when the head was elevated using MP (Figure 1).

First, each participant was asked to sit on a chair in a quiet room under dim light conditions. Ten minutes later, IOP was measured in the sitting position. Then, the participant was asked to lie down on a bed, flat or head-up according to the sequence predetermined in the aforementioned manner. We measured IOP $10 \mathrm{~min}$ after adopting each posture. For head-up postures, two different methods were used: (1) one half of the bed, where the head and the upper torso were rested, was elevated at $30^{\circ}$ (BHE); and (2) two or three pillows were placed underneath the subject's head (MP) so that the level of both eyes would be the same as in the BHE method (Figure 1).

\section{Statistics}

A pilot study revealed that the SD of IOP difference of right eye between the two head-up positions (BHE vs $\mathrm{MP})$ was $2.9 \mathrm{~mm} \mathrm{Hg}(2.9 \mathrm{~mm} \mathrm{Hg}$ for left eye). A sample size calculation, using $\mathrm{G}^{*}$ Power software (version 3.0.10; Universität Kiel Dusseldorf, Germany) with $\alpha=0.05$, determined that 24 patients would be required to detect an IOP difference of $>2.0 \mathrm{~mm} \mathrm{Hg}$ between those two different head-up positions at a SD of $2.9 \mathrm{~mm} \mathrm{Hg}$ during changes of head elevation with a power of $80 \%$.

All statistical analyses were performed using SPSS version 18.0 (SPSS Inc., Chicago, IL, USA). The Wilcoxon signed-rank test was used to compare the axial length, central corneal thickness, refractive errors, and IOP 

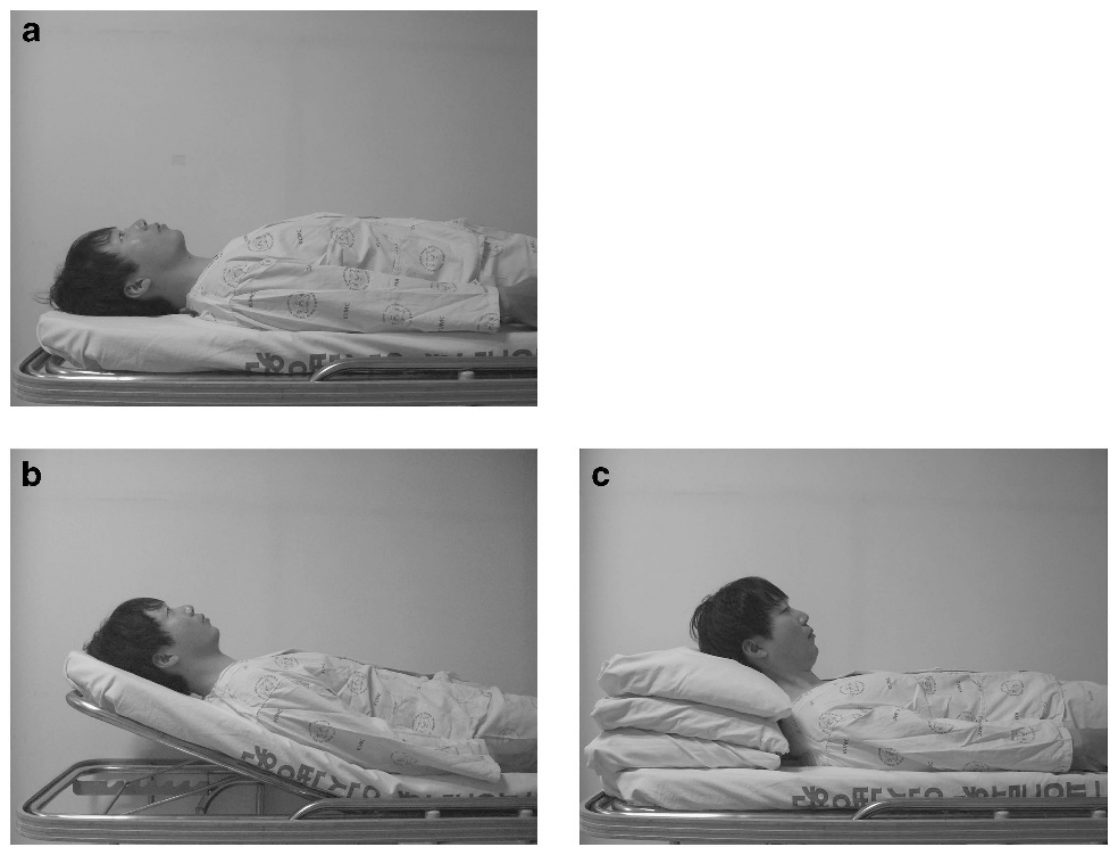

Figure 1 Supine postures with different head positions: flat position (a); head-up position obtained by raising the head of bed by $30^{\circ}$ (b); head-up position obtained by placing MP beneath the head of the subject (c). Note that the height of the eyes from the ground is the same in (b) and (c).

measured by Goldmann applanation tonometer, and also to assess the intereye IOP differences in each position. The Wilcoxon signed-rank test with Bonferroni correction was used to compare the IOP by changing the methods of head elevation. A $P$-value $<0.05$ was considered significant unless the Bonferroni correction method for multiple comparison was utilized, in which case a $P<0.017$ was considered significant.

\section{Results}

Twenty-four subjects participated in this study. Thirteen subjects were male and 11 were female with a mean age of $26.7 \pm 1.3$ years. The subjects' demographic data are summarized in Table 1. Mean IOPs by Goldmann applanation tonometry, mean refractive errors (spherical equivalent), mean axial lengths, and mean central corneal thickness did not differ between fellow eyes of the subjects.

Table 2 lists the IOP measurements obtained in the sitting position and in the supine positions with the head flat or elevated using different methods. No significant difference was found between fellow eyes in the sitting position as well as in all the recumbent positions.

Mean IOP of both eyes when sitting was lower than that measured lying in the flat position $(P=0.001)$. Compared with that measured in the supine position with the head flat, mean IOP was lower when measured in the supine position with the head up by BHE (right eye, $-2.6 \mathrm{~mm} \mathrm{Hg}$; left eye, $-2.9 \mathrm{~mm} \mathrm{Hg}$, both $P=0.001$ ),
Table 1 Baseline characteristics of subjects $(n=24)$

\begin{tabular}{lccc}
\hline & Right eye & Left eye & P-value $^{\mathrm{a}}$ \\
\hline IOP $(\mathrm{mm} \mathrm{Hg})$ & $13.4 \pm 2.1$ & $13.0 \pm 2.2$ & 0.103 \\
SE (diopter) & $-2.78 \pm 2.55$ & $-2.54 \pm 2.59$ & 0.635 \\
AL $(\mathrm{mm})$ & $25.1 \pm 1.2$ & $25.0 \pm 1.1$ & 0.909 \\
CCT $(\mu \mathrm{m})$ & $547.9 \pm 29.9$ & $551.2 \pm 25.0$ & 0.932 \\
\hline
\end{tabular}

Abbreviations: $\mathrm{AL}$, axial length; $\mathrm{CCT}$, corneal central thickness; IOP, intraocular pressure; SE, spherical equivalent.

${ }^{a}$ Wilcoxon singed-rank test.

Table 2 Intraocular pressure in the sitting and the supine positions with head flat and elevated using different methods

\begin{tabular}{lccc}
\hline Position & \multicolumn{3}{c}{ Intraocular pressure $(\mathrm{mm} \mathrm{Hg})$} \\
\cline { 2 - 4 } & $\begin{array}{c}\text { Right eye } \\
\text { (mean } \pm \text { SD) }\end{array}$ & $\begin{array}{c}\text { Left eye } \\
\text { (mean } \pm S D)\end{array}$ & P-value \\
\hline Sitting & $13.5 \pm 2.0$ & $13.2 \pm 2.3$ & 0.139 \\
Supine flat & $16.8 \pm 2.3$ & $17.0 \pm 2.3$ & 0.318 \\
Supine head-up with BHE & $14.2 \pm 2.3$ & $14.1 \pm 1.9$ & 0.908 \\
Supine head-up with MP & $16.3 \pm 2.4$ & $16.5 \pm 2.6$ & 0.547 \\
\hline
\end{tabular}

Abbreviaitons: BHE, bed head elevation; MP, multiple pillows.

${ }^{\text {a } W i l c o x o n ~ s i n g e d-r a n k ~ t e s t . ~}$

whereas mean IOP was not significantly different when measured in the supine position with the head up by MP (right eye, $P=0.061$; left eye, $P=0.089$ ) (Table 2,

Figure 2). Compared between two different methods of head elevation, mean IOP was lower when the head was kept up with BHE (both right and left eye, $P=0.001$ ). 
Figure 3 shows the average changes of IOP seen with two different head-elevating methods in each individual. Compared with the head flat position, all but one subject (95.8\%) had lower IOP in the BHE head-up position. The average IOP reduction in the BHE position was $15.9 \pm 8.2 \%$ with $20(83.3 \%)$ subjects having IOP reduction $>10 \%$. However, only $14(58.3 \%)$ subjects had lower IOP in the MP head-up position. Four $(16.5 \%)$ had similar IOP and six $(25 \%)$ subjects had even higher IOP in the MP head-up position.

\section{Discussion}

Postural modification has long been used as adjuctive therapy in the management of several diseases such as congestive heart failure, obstructive sleep apnea, bronchial asthma, and gastroesophageal reflux. ${ }^{29}$ Positioning of the head and body is also important in the management of retinal disorders. Prone positioning is commonly recommended to the vitrectomized patients in the early postoperative period to promote the attachment of retinal breaks. ${ }^{30}$ In cases with inferior retinal breaks, patients are asked to keep the head up to prevent the expansion of the breaks while awaiting vitreoretinal surgeries. Head-up positioning is also recommended to patients with vitreous hemorrhages and hyphema.

Recently, there have been some papers on the beneficial effects of sleeping with the head up on IOP. Buys et $a l^{26}$ investigated the 24-h IOP and blood pressure in 17 normal-tension glaucoma patients with controlled office IOPs and new disc hemorrhages. In their study, the $30^{\circ}$ head-up sleeping position lowered IOP by $3.2 \mathrm{~mm} \mathrm{Hg}$ without significant alteration in ocular perfusion pressure compared with the flat position. Lazzaro et $a l^{27}$ also studied the effect of sleeping in a $20^{\circ}$ head-up position in 15 glaucoma patients and 15 nonglaucoma patients. They demonstrated lower nocturnal IOPs $(-1.5 \mathrm{~mm} \mathrm{Hg})$ with

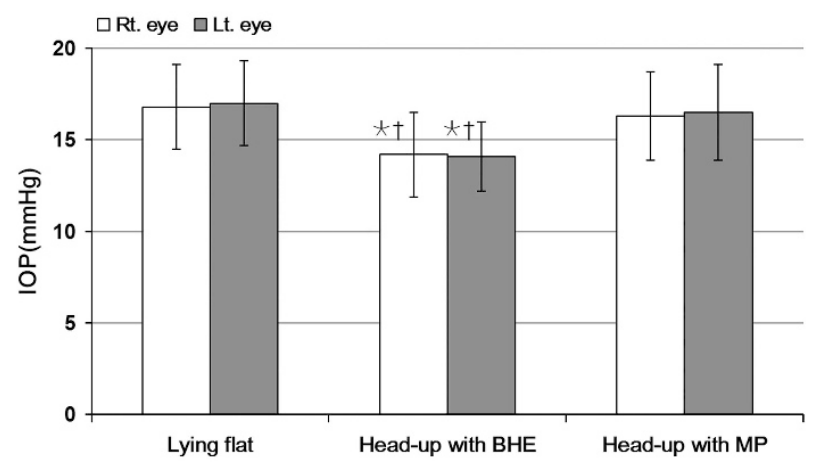

Figure 2 IOP in the sitting and the supine positions was measured with the head kept flat and elevated using different methods. Wilcoxon singed-rank test for multiple comparisons using Bonferroni correction was performed. ${ }^{*} P<0.003$ vs lying flat, ${ }^{\dagger} P<0.003$ vs MP. head-up position as compared with the head-flat position in patients with and without glaucoma. In agreement with these findings, the present study found a significant drop in IOP $(-2.8 \mathrm{~mm} \mathrm{Hg})$ when measured in a $30^{\circ}$ head-up position with BHE compared with the flat position. In terms of level of IOP, these observations together suggest a potentially beneficial role of postural change in the management of glaucoma.

Although the head-up positioning has consistently been shown to lower IOP in patients with or without glaucoma, it is important to note as to how the head was kept up in those studies. In the two previous studies, ${ }^{26,27}$ a wedge pillow was used for head-up positioning. In our study, we kept the patient's head up by elevating the head of the bed. By using either method, not only the head but also the upper torso is raised. However, few studies have investigated as to how other methods of head elevation influence IOP.

In addition to wedge pillows and BHE, one can use MP to keep the head up during sleep. In many Asian countries, a number of people sleep on the floor and wedge pillows are not used commonly. For such non-bed users, sleeping in a head-up position translates into using MPs when a wedge pillow is not available. In the present study, we found that the head elevation using MP did not lower IOP when compared with the flat position.

Compared with the BHE, IOP was significantly higher with the MP. To our knowledge, this is the first study to investigate the effect of the head elevation using MP on IOP.

Unlike the other methods that provide elevation of the entire upper torso, using MP leads to elevation of only the head and neck. The resultant craniocervical flexion may compress the neck vessels and increase episcleral venous pressure, thereby offsetting the IOP decrease seen with the other head-elevating methods. In line with this,

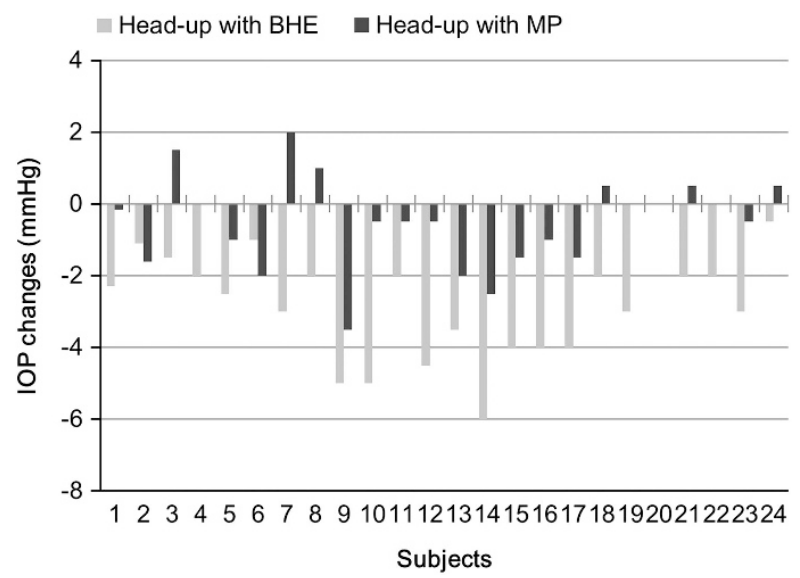

Figure 3 Individual changes in IOP with alterations of head position from the flat to the elevated position using two different methods. 
Malihi and $\mathrm{Sit}^{20}$ found a significant increase in IOP during neck flexion when measured in the sitting position in healthy subjects. In the current study, we found that IOP even increased in 6 of the 24 subjects when the head was elevated with MP compared with that measured in the flat position. Such an elevation in IOP was not found with the BHE method in any of the participants in this study. Although it needs to be studied and confirmed in glaucoma patients, our findings suggest that using MP may not be a good way of keeping the head up for all glaucoma patients in bed.

This study has some limitations. First, the study includes only healthy young individuals. Hence, the current study finding cannot be directly extrapolated into glaucoma patients or elderly subjects. Second, we did not perform IOP measurements under nocturnal sleeping conditions in a sleep laboratory. Multiple physiologic and environmental conditions may affect IOP in nocturnal and wake periods. The laboratory environment of this study cannot reflect the same physiologic and environmental conditions of subjects. Third, the short duration of maintaining each position and keeping the head elevated at a fixed angle $\left(30^{\circ}\right)$ may be another limitation. The magnitude of IOP alterations may fluctuate according to the duration of time spent and the degree of tilt in various positions. ${ }^{31}$ Fourth, we did not check ocular perfusion and cerebrospinal fluid pressure. Low ocular perfusion pressure ${ }^{32}$ and low cerebrospinal perfusion pressure ${ }^{6}$ may have a role in the development of glaucoma.

In conclusion, head elevation-induced IOP reduction may not be obtained when the head is kept up using MP. These findings suggest that elevating the head using MP may not help to reduce IOP in supine postures. However, further studies are required to verify the clinical implications of our observations.

\section{Summary}

What was known before

- Body posture is one of the factors influencing the fluctuation of IOP.

- Recent studies investigated the effect of sleeping in a head-up position on IOP in healthy subjects and glaucoma patients.

- Compared with the head-flat position, IOP was lower when the head was elevated using a wedge pillow.

What this study adds

- Methods of head elevation also include raising the bed head and using MP.

- Elevation of the bed head significantly lowered IOP in healthy subjects.

- The present study found that head elevation using MP may not lower IOP when compared with the flat position.

\section{Conflict of interest}

The authors declare no conflict of interest.

\section{References}

1 Heijl A, Leske MC, Bengtsson B, Hyman L, Bengtsson B, Hussein $\mathrm{M}$ et al. Reduction of intraocular pressure and glaucoma progression: results from the Early Manifest Glaucoma Trial. Arch Ophthalmol 2002; 120(10): 1268-1279.

2 Kass MA, Heuer DK, Higginbotham EJ, Johnson CA, Keltner JL, Miller JP et al. The ocular hypertension treatment study: a randomized trial determines that topical ocular hypotensive medication delays or prevents the onset of primary open-angle glaucoma. Arch Ophthalmol 2002; 120(6): 701-713.

3 Memarzadeh F, Ying-Lai M, Chung J, Azen SP, Varma R. Los Angeles Latino Eye Study Group. Blood pressure, perfusion pressure and open angle glaucoma: the Los Angeles Latino eye study. Invest Ophthalmol Vis Sci 2010; 51: 2872-2877.

4 Sommer A, Tielsch JM, Katz J, Quigley HA, Gottsch JD, Javitt JC et al. Racial differences in the cause-specific prevalence of blindness in East Baltimore. $N$ Engl J Med 1991; 325: 1412-1417.

5 Mitchell P, Hourihan F, Sandbach J, Wang JJ. The relationship between glaucoma and myopia: the Blue Mountains eye study. Ophthalmology 1999; 106: 2010-2015.

6 Berdahl JP, Allingham RR. Intracranial pressure and glaucoma. Curr Opin Ophthalmol 2010; 212: 106-111.

7 Collaborative Normal-Tension Glaucoma Study Group. The effectiveness of intraocular pressure reduction in the treatment of normal tension glaucoma. Am J Ophthalmol 1998; 126: 498-505.

8 Stamper RL, Lieberman MF, Drake MV (eds) Medical treatment of glaucoma: general principles. In: BeckerShaffer's Diagnosis and Therapy of the Glaucomas. 8th edn Mosby: Philadelphia, PA, USA, 2009, p 346.

9 Chobanian AV, Bakris GL, Black HR, Cushman WC, Green LA, Izzo Jr, JL et al. Seventh report of the Joint National Committee on prevention, detection, evaluation, and treatment of high blood pressure. Hypertension 2003; 42: 1206-1252.

10 Liu JH, Sit AJ, Weinreb RN. Variation of 24-hour intraocular pressure in healthy individuals: right eye versus left eye. Ophthalmology 2005; 112: 1670-1675.

11 Liu JH. Circadian rhythm of intraocular pressure. J Glaucoma 1998; 7: 141-147.

12 Liu JH, Kripke DF, Hoffman RE, Twa MD, Loving RT, Rex KM et al. Nocturnal elevation of intraocular pressure in young adults. Invest Ophthalmol Vis Sci 1998; 39: 2707-2712.

13 Tsukahara S, Sasaki T. Postural change of IOP in normal persons and inpatients with primary wide open-angle glaucoma and low-tension glaucoma. Br J Ophthalmol 1984; 68: 389-392.

14 Noël C, Kabo AM, Romanet JP, Montmayeur A, Buguet A. Twenty-four-hour time course of intraocular pressure in healthy and glaucomatous Africans: relation to sleep patterns. Ophthalmology 2001; 108: 139-144.

15 Liu JH, Zhang X, Kripke DF, Weinreb RN. Twenty-four-hour intraocular pressure pattern associated with early glaucomatous changes. Invest Ophthalmol Vis Sci 2003; 44: 1586-1590.

16 Kiuchi T, Motoyama Y, Oshika T. Relationship of progression of visual field damage to postural changes in 
intraocular pressure in patients with normal tension glaucoma. Ophthalmology 2006; 113: 2150-2155.

17 Kiuchi T, Motoyama Y, Ochika T. Postural response of intraocular pressure and visual field damage in patients with untreated normal-tension glaucoma. J Glaucoma 2010; 19: 191-193.

18 Hwang JW, Jeon YT, Kim JH, Oh YS, Park HP. The effect of the lateral decubitus position on the intraocular pressure in anesthetized patients undergoing lung surgery. Acta Anaesthesiol Scand 2006; 50: 988-992.

19 Lee JY, Yoo C, Jung JH, Hwang YH, Kim YY. The effect of lateral decubitus position on intraocular pressure in healthy young subjects. Acta Ophthalmol 2012; 90: e68-e72.

20 Malihi M, Sit AJ. Effect of head and body position on intraocular pressure. Ophthalmology 2012; 119: 987-991.

21 Lee JY, Yoo C, Kim YY. The effect of lateral decubitus position on intraocular pressure in patients with untreated open-angle glaucoma. Am J Ophthalmol 2013; 133: 329-335.

22 Kim KN, Jeoung JW, Park KH, Lee DS, Kim DM. Effect of lateral decubitus position on intraocular pressure in glaucoma patients with asymmetric visual field loss. Ophthalmology 2013; 120: 731-735.

23 Lee TE, Yoo C, Kim YY. Effects of different sleeping postures on intraocular pressure and ocular perfusion pressure in healthy young subjects. Ophthalmology 2013; 120: 1565-1570.

24 Wong MH, Lai AH, Singh M, Chew PT. Sleeping posture and intraocular pressure. Singapore Med J. 2013; 54: 146-148.
25 Kim KN, Jeoung JW, Park KH, Kim DM, Ritch R. Relationship between preferred sleeping position and asymmetric visual field loss in open-angle glaucoma patients. Am J Ophthalmol 2014; 157: 739-745.

26 Buys YM, Alasbali T, Jin YP, Smith M, Gouws P, Geffen N et al. Effect of sleeping in a head-up position on IOP in patients with glaucoma. Ophthalmology 2010; 117: 1348-1351.

27 Lazzaro EC, Mallick A, Singh M, Reich I, Elmann S, Stefanov DG et al. The effect of positional changes on intraocular pressure during sleep in patients with and without glaucoma. J Glaucoma 2014; 23: 282-287.

28 Fogagnolo P, Orzalesi N, Ferreras A, Rossetti L. The circadian curve of intraocular pressure: can we estimate its characteristics during office hours? Invest Ophthalmol Vis Sci 2009; 50: 2209-2215.

29 Martin-Du Pan RC, Benoit R, Girardier L. The role of body position and gravity in the symptoms and treatment of various medical diseases. Swiss Med Wkly 2004; 134: 543-551.

30 Yoon $\mathrm{YH}$, Sheu S, Taraskia H. Primary vitrectomy in rhegmatogenous retinal detachment. In: Ryan SJ (eds) Retina. 5th ed. Mosby: Philadelphia, PA, USA, 2013, pp 1715.

31 Linder BJ, Trick GL, Wolf ML. Altering body position affects intraocular pressure and visual function. Invest Ophthalmol Vis Sci 1988; 29: 1492-1497.

32 Leske MC. Ocular perfusion pressure and glaucoma: clinical trial and epidemiologic findings. Curr Opin Ophthalmol 2009; 20: 73-78. 